\title{
A comparative study of the contact fatigue behavior and associated damage micromechanisms of TiN- and WC:H-coated cold-work tool steel
}

\author{
G. Ramírez ${ }^{\mathrm{a}, \mathrm{b}, \mathrm{n}}$, E. Jiménez-Piqué ${ }^{\mathrm{a}, \mathrm{c}}$, A. Mestra ${ }^{\mathrm{a}, \mathrm{c}}$, M. Vilaseca $^{\mathrm{b}}$, D. Casellas ${ }^{\mathrm{b}}$, L. Llanes ${ }^{\mathrm{a}, \mathrm{c}}$ \\ CIEFMA - Departament de Ciència dels Materials i Enginyeria Metallúrgica, Universitat Politècnica de Catalunya, ETSEIB, Av. Diagonal 647, \\ 08028 Barcelona, Spain \\ b Fundació CTM Centre Tecnològic, Plaça de la Ciència, 208243 Manresa (BCN), Spain \\ CRnE - Campus Diagonal Sud, Universitat Politècnica de Catalunya, C. Pascual i Vila 15, 08028 Barcelona, Spain
}

In this study the contact fatigue behavior of two coated tool steel is compared. They differ in the chemical nature of the coatings as well as on the deposition route used: a conventional TiN coating prepared by cathodic arc technique, and a sputtered WC:H thin film. Both of them have been deposited upon the same wrought tool steel. The mechanical response under cyclic contact loads is assessed by means of spherical indentation. It is found that the WC:H-coated system exhibits an improved contact fatigue behavior with respect to that of the TiN-one, as cohesive and adhesive damage are completely inhibited in the former. Such finding is rationalized on the basis of effective reduction of stresses associated with microasperity contacts.

\& 2015 Elsevier Ltd. All rights reserved.

\section{Introduction}

Susceptibility of coated tool steels to coating delamination associated with repetitive contact loading is well-established (e.g. see Refs. [1-6]). Under these service conditions, such failure scenario results from the conjugation of two different phenomena at the coating/ substrate interface: (1) downward extension of cohesive damage originated at the film surface and (2) upward propagation of cracks nucleated at primary carbides within the substrate [7]. Hence, as it is also the case in any other tribology-related application, improvement of contact fatigue strength of coated tool steels requires microstructural/processing considerations at all levels: substrate material, surface preparation, coating nature and surface topography (e.g. see Ref. [8]). 
In a previous work by the authors, efforts concentrated on evaluating microstructural influence of the steel substrate on the contact fatigue strength of TiN-coated systems $[7,9,10]$. As a result, it was found that adhesive failure induced by repetitive contactloading was delayed (an even inhibited) by using cold-work tools steels with finer, rounded and homogeneously distributed primary carbides. However, further improvement on the performance of such coated tools recalls additional actions regarding both coating and surface topography. As it has been referred above, the fatigueinduced detachment of the TiN film required premature cohesive damage within the coating. In this regard, droplets developed during the cathodic arc deposition process were identified to play a critical role as detrimental seeds for cohesive failure [7]. These surface defects were also responsible for the relatively high roughness exhibited by the TiN coating studied. Hence, the deposition of a thin film with enhanced surface roughness and surface-free defects should be considered if performance wants to be improved further. Moreover, friction, galling and oxidation responses represent a critical issue for contact-related applications. Concerning the former, this is particularly true for dried or limited lubrication applications, as lower friction coefficients ensure that maximum shear stresses are well below the surface (i.e. far from coating or interface) $[8,11]$. In this regard, metal containing amorphous hydrogenated diamond-like carbon films $(\mathrm{Me}-\mathrm{C}: \mathrm{H}$ or Me-DLC) deposited by a sputtering PVD (Physical Vapor Deposition) technique must be postulated as ideal choices. These coatings present excellent tribological properties, even at a relatively high surface roughness [11-17]. The metallic elements, such as tungsten, are incorporated into the films in form of nanocarbides to increase the coating adhesion and tribological properties. Me-C:H coatings have been successful applied in various automotive components $[8,18]$, especially in those where high contact pressures can be achieved (e.g. gears, bearings, piston rings and the cam/tappet contact). It is then the aim of this work such as tungsten, are incorporated into the films in form of nanocarbides to increase the coating adhesion and tribological properties. Me-C:H coatings have been successful applied in various automotive components $[8,18]$, especially in those where high contact pressures can be achieved (e.g. gears, bearings, piston rings and the cam/tappet contact). It is then the aim of this work

\begin{tabular}{|c|c|c|c|}
\hline $\mathrm{D}_{\text {eq }}[\mu \mathrm{m}]$ & $D_{\max }[\mu m]$ & Shape factor & A wrought cold work tool steel was chosen as a base \\
\hline 7 & 25 & $\begin{array}{l}0.2-0.5 \\
\left(\mathrm{M}_{7} \mathrm{C}_{3}\right) / 0.4-0.8 \\
(\mathrm{MC})\end{array}$ & $\begin{array}{l}\text { material. It was heat treated such to attain a mean } \\
\text { hardness of } 61-62 \text { HRC. This steel was developed by } \\
\text { Rovalma and is commercially referred to as }\end{array}$ \\
\hline
\end{tabular}




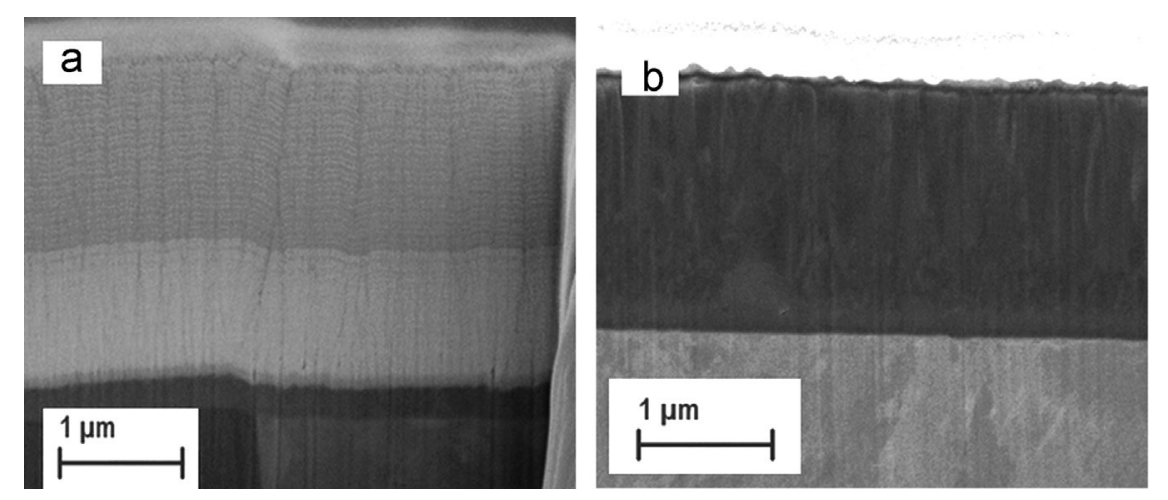

Fig. 1. Focus Ion Beam (FIB) micrographs of (a) the titanium nitride coating, and (b) the multilayer structure of WC:H coating.

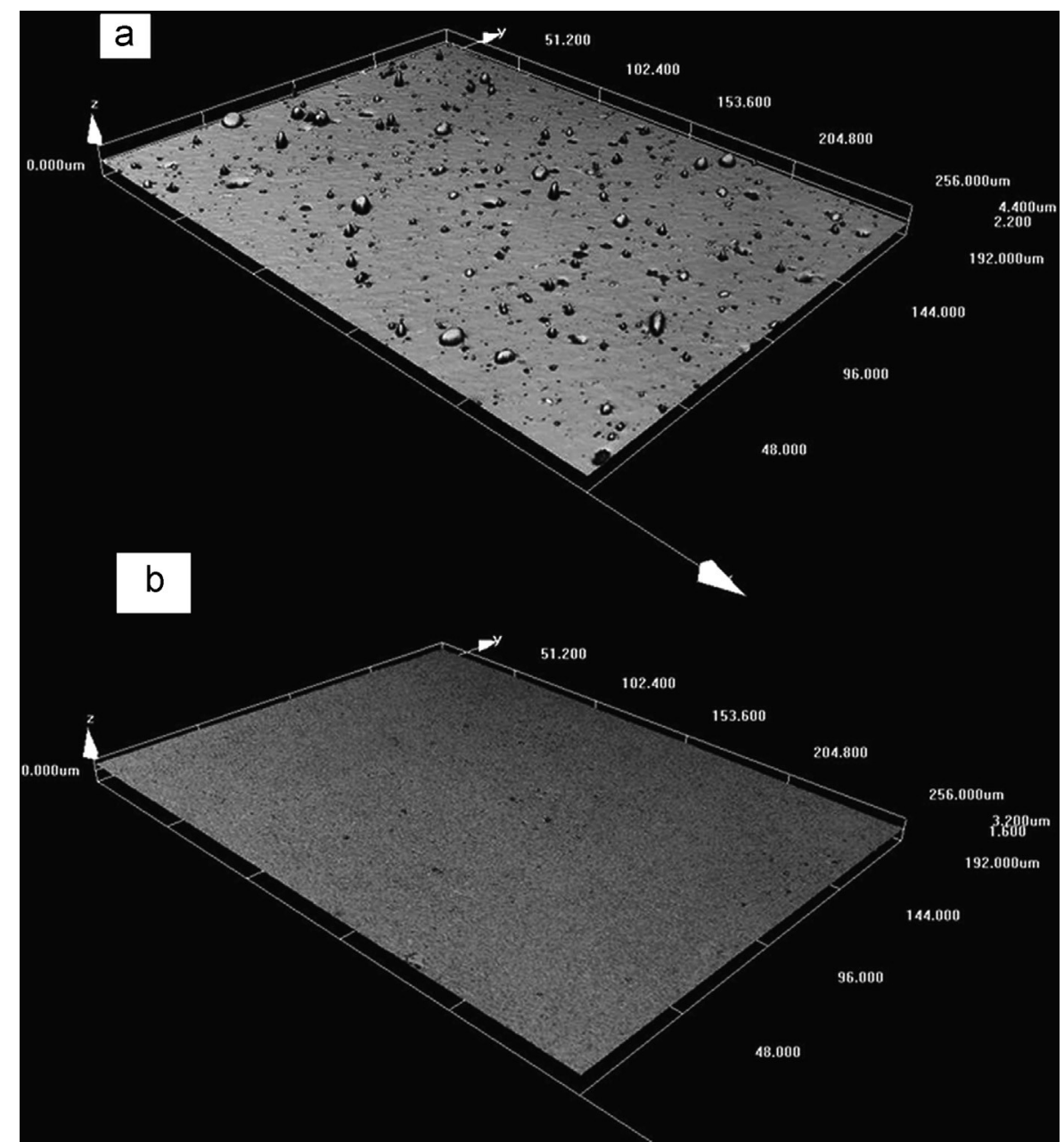

Fig. 2. Surface topography of (a) TiN and (b) WC:H coatings.

UNIVERSAL. Regarding microstructural features [19], UNIVERSAL contains two types of primary carbides: $\mathrm{M}_{7} \mathrm{C}_{3}$, where $\mathrm{M}$ is $35-45 \% \mathrm{Cr}, 10-20 \% \mathrm{~V}, 35-45 \% \mathrm{Fe}$ and $2-4 \% \mathrm{~W}$; and $\mathrm{MC}$, where $\mathrm{M}$ is $50-$ $70 \% \mathrm{~V}, 8-10 \% \mathrm{Cr}$ and $7-12 \% \mathrm{~W}$. These carbides are aligned in the hot working direction within a tempered martensitic matrix. In Table 1 , the size and morphology parameters of primary carbides are expressed in terms of the average equivalent diameter $\left(D_{\text {eq }}\right)$, the maximum diameter $\left(D_{\max }\right)$ and shape 
factor. The latter is defined as the ratio between the minimal and maximal length of carbide, and thus being equal to one for a spherical particle. $\mathrm{M}_{7} \mathrm{C}_{3}$ carbides of UNIVERSAL steel are discerned to keep the elongated shape conventionally observed in cold work tool steels, whereas MC ones are more spherical.

\subsection{Coatings and characterization techniques}

TiN and WC:H (or W-DLC) coatings were deposited on a mirror polished side of tool steel samples with an arithmetic mean surface roughness $\left(\mathrm{R}_{\mathrm{a}}\right)$ values between 0.02 and $0.03 \mathrm{~mm}$. Both coatings were deposited by AIN (Navarra Industry Association). The reference TiN coating was prepared by reactive cathodic vacuum arc evaporation in a METAPLAS MZR 323 system, and the deposition parameters used for this coating have been described elsewhere [7].

The WC doped hydrogenated diamond like carbon was deposited by unbalance magnetron sputtering process using a METAPLAS IONON MZR 323 machine. WC:H coating prepared had a three-layer structure: a first cladding one of chromium ( $\mathrm{Cr}$ target $99.9 \%$ purity) to improve coating adhesion; then a second hard coating of WC (WC target $99.8 \%$ purity) aimed to provide load-bearing capacity; and a final carbon-graded WC:H layer for optimizing tribological performance. The substrate surface was previously cleaned by Arp ion etching and annealed in vacuum at 350 1C. The chromium layer was deposited by dc magnetron sputtering $\left(4.3 \mathrm{~W} / \mathrm{cm}^{2}\right.$ of power density and $50 \mathrm{~V}$ of substrate bias). The substrate bias during growth was set to $50 \mathrm{~V}$. The evolution of $\mathrm{Cr}$ to $\mathrm{WC}$ layer was achieved with a power density of $5.7 \mathrm{~W} / \mathrm{cm}^{2}$. For the low-friction WC:H layer, the $\mathrm{C}_{2} \mathrm{H}_{2}$ flow was progressively increased from 5 to $10 \mathrm{sccm}$.

Microstructural features of the deposited coatings were inspected by scanning electron microscopy (SEM) of cross-sections milled by using a focused ion beam (FIB). Both actions were conducted by employing a dual beam Workstation (Zeiss Neon 40). Surface topography and roughness were measured by Confocal Laser Scanning Microscope (CLSM) LEXT OLS3100.

Profile composition was obtained through a glow discharge optical emission spectroscopy (GDOES) technique using a JY 10000RF equipment with a RF source. The source was operated at constant pressure and applied power of $650 \mathrm{~Pa}$ and $40 \mathrm{~W}$, respectively. The emission lines (wavelengths in $\mathrm{nm}$ ) used were: $\mathrm{Ti}$ (365.350), N (149.262), C (156.144), Cr (425.433), and W (401.000).

\subsection{Mechanical characterization}

The mechanical characterization of the coated system included evaluation of the effective hardness of coating through instrumented indentation. It was performed using a nanoindenter (MTS Nanoindenter XP) equipped with a continuous stiffness measurement module, employing a diamond Berkovich indenter. Sixteen indentations were done under load control and at constant strain rate of $0.05 \mathrm{~s}^{1}$. Indentation loaddepth curves were analyzed according to the Oliver and Pharr method [20], and the results were averaged to obtain the effective hardness as a function of indentation depth.

Assessment of the mechanical contact response of the coated systems by means of spherical indentation was the main experimental activity of this investigation. Tests were performed in a servohydraulic testing machine (Instron 8511) using hardmetal balls with $1.25 \mathrm{~mm}$ of curvature radius as indenters. Monotonic loading was conducted following a trapezoidal waveform, at a loading rate of $30 \mathrm{~N} \mathrm{~s}^{1}$ and applying the full test force during $20 \mathrm{~s}$. On the other hand, cyclic loading was imposed by means of a sinusoidal waveform at 
a frequency of $10 \mathrm{~Hz}$ and using a load ratio of 0.1 . Fatigue tests were performed till five different cyclic periods: $10^{3}, 10^{4}, 10^{5}, 210^{5}$, and $10^{6}$
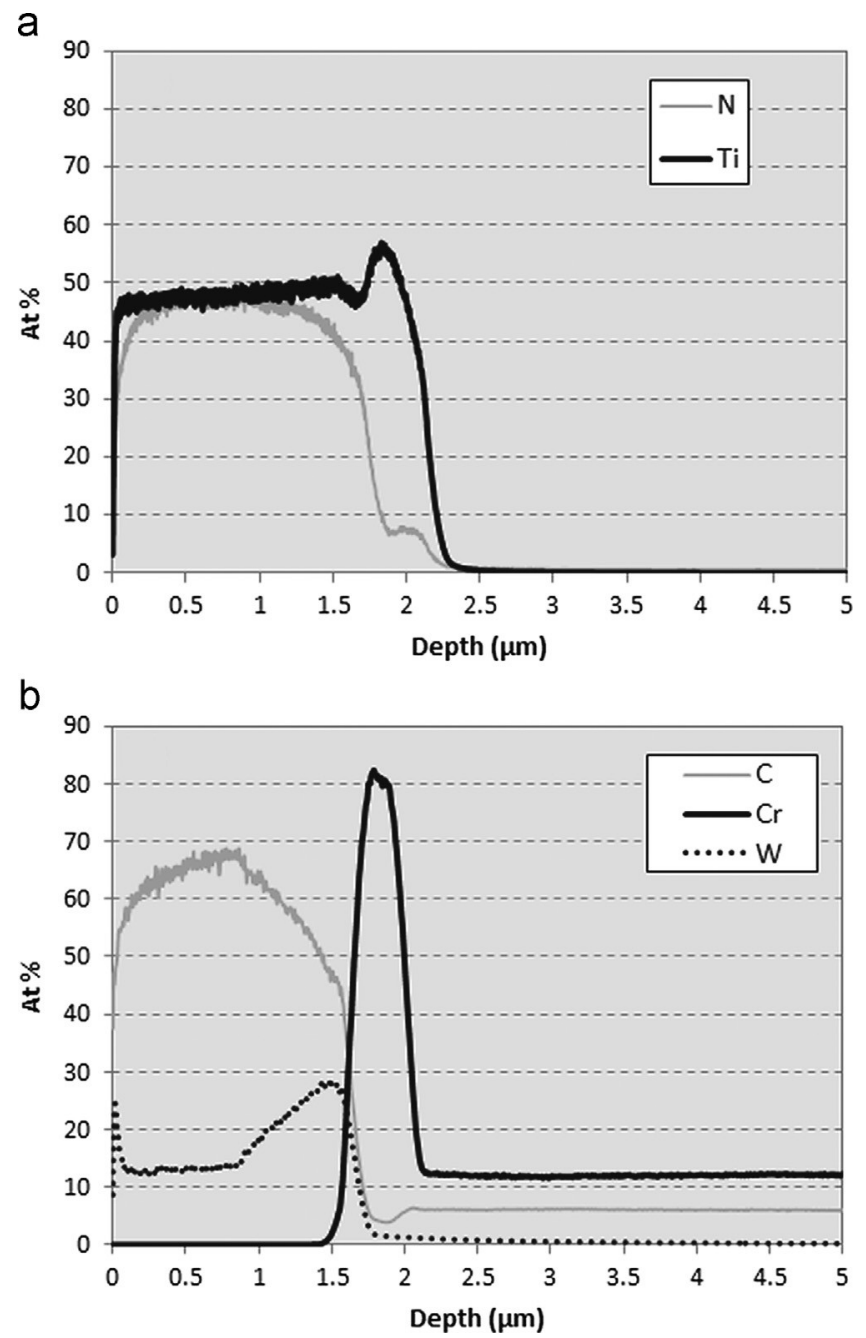

Fig. 3. Quantitative atomic composition in depth profiles for (a) TiN and (b) WC:H coatings.

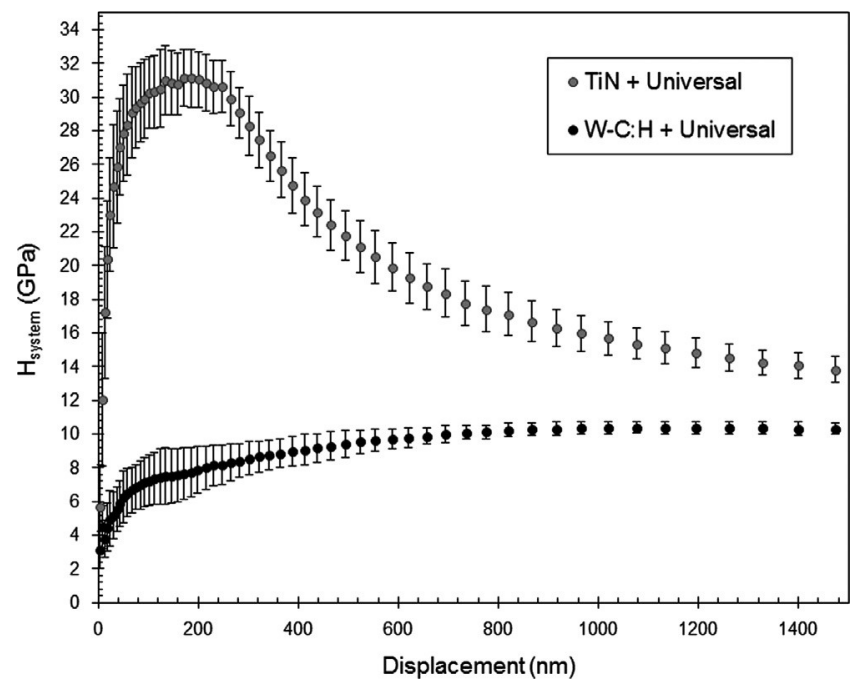


Fig. 4. Effective hardness for TiNpUNIVERSAL and WC:HpUNIVERSAL coated systems as a function of indentation depth.

cycles. All tests were conducted under maximum applied load of $800 \mathrm{~N}$, as this was the minimum level determined for attaining coating delamination (after a high enough number of cycles) in the reference TiNUniversal system in a previous work [7]. At least three indentations were applied per each testing condition.

Residual imprint depth as well as the damage evolution was inspected and recorded by CLSM. Regarding the latter, special attention was paid to discern emergence of different damage events: circumferential/radial cracks, cohesive spalling and/or adhesion (delamination) failure. For comparison purposes, high-cycle fatigue testing was also conducted on the uncoated steel substrate. Finally, substrate/ coating interaction regarding damage micromechanisms, in terms of both nucleation and propagation, was inspected by FIB milling of cross sections at the periphery of indentation residual imprints. This study was conducted at specific locations where damage events were clearly identified.

\section{Results and discussion}

\subsection{Characterization of coatings}

A fine-grained columnar structure may be discerned in Fig. 1 for both coatings studied. The metallic interlayers are clearly evidenced in both cases as well as the multilayer structure exhibited by the WC:H coating. Thickness are about 2 and $3 \mu \mathrm{m}$ for TiN and WC:H coatings, respectively.

After deposition of titanium nitride, the surface roughness parameter $\left(R_{a}\right)$ for the coated system increased significantly, from $0.03 \mu \mathrm{m}$ to $0.33 \mu \mathrm{m}$. This roughness change is a direct consequence of the presence of droplets at the TiN surface, as it is observed in Fig. 2a. These microstructural heterogeneities are typically present in films deposited by cathodic arc evaporation [21], and may be formed during the ion cleaning stage before coating deposition, or incorporated in the solid state during the film growth. On the other hand, roughness value remains similar after deposition of the $\mathrm{WC}: \mathrm{H}$ layer, as expected from the droplet-free surface exhibited by this sputtering-PVD coating (Fig. 2b).

The atomic composition of the reference TiN layer is shown as a function of the depth from the surface in Fig. 3a. From the spectra, it is evidenced a Ti-rich interlayer at the substrate-coating interface. It is introduced within the coated system to improve the coating adhesion as well as to reduce stresses at the interface. Similar analysis for WC:H coating is shown in Fig. 3b. WC:H coating may be described as exhibiting a multilayer structure composed of a chromium bond interlayer, upon which a WC containing transition film is deposited. The functional WC:H low-friction coating forms at the top of this compound and consists of graded carbon composition ranging from 40 at $\%$ at the interface with the Cr layer up to $60-$ 70 at $\%$ close to the surface.

\subsection{Instrumented indentation}

The variation in hardness with indentation depth for the studied coatings is shown in Fig. 4. Intrinsic hardness, assessed at around $10 \%$ of the coating thickness, for the films are $3172 \mathrm{GPa}$ and $872 \mathrm{GPa}$ for TiN 
and $\mathrm{WC}: \mathrm{H}$, respectively. The fact that carbon contribution within the top low-friction exceeds 50 at $\%$ of the total carbon concentration
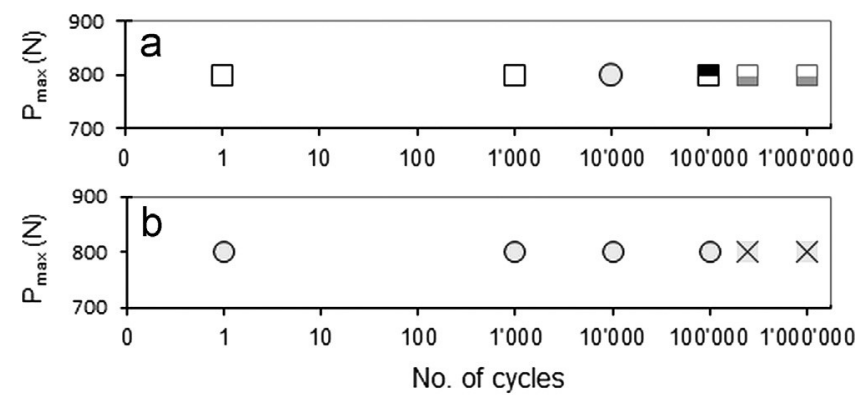
$\square$ Delamination
$\times$ Radial Craks
曰 Cohesive damage
o Circumferential cracks

Fig. 6. Maximum applied load vs. number of cycles diagram describing damage evolution under spherical contact fatigue for: (a) TiN and (b) WC:H deposited in UNIVERSAL steel.

of carbonaceous species leads to an extreme decrease of the coating hardness close to the surface [22-24]. As a consequence, hardness profile exhibits an increasing trend with penetration depth, from values lower than $5 \mathrm{GPa}$ at the top surface up to maximum value of $10 \mathrm{GPa}$ defined by the substrate contribution to loadbearing capacity.
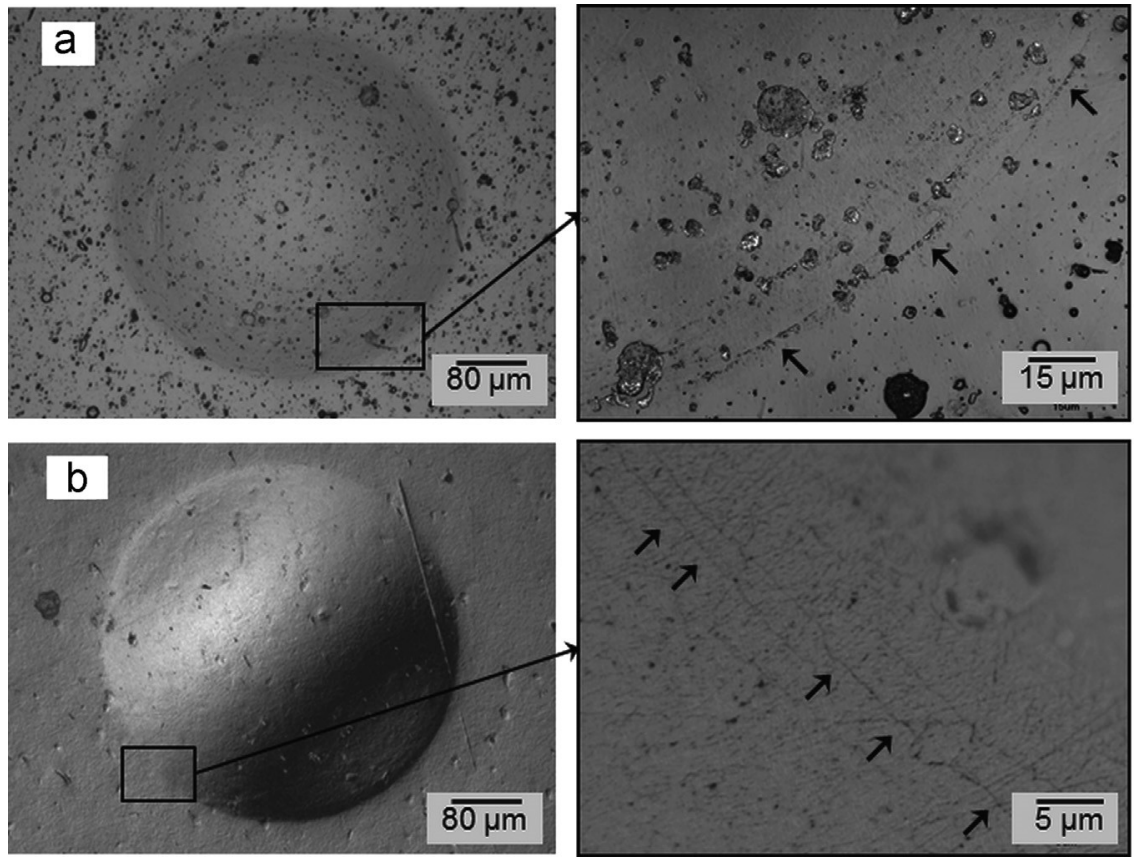

g. 5. Circumferential cracks appearance at the edge of residual imprints when a maximum load of $800 \mathrm{~N}$ as applied. Cracks in (a) TiN surface was evidenced after $10^{3}$ cycles, and damage on (b) WC:H surface was scerned under monotonic loading condition. 


\subsection{Spherical indentation}

The evolution of damage induced by the spherical indenter on coated specimens was assessed by means of CLSM. Under an applied load of $800 \mathrm{~N}$ with the hardmetal indenter of $1.25 \mathrm{~mm}$
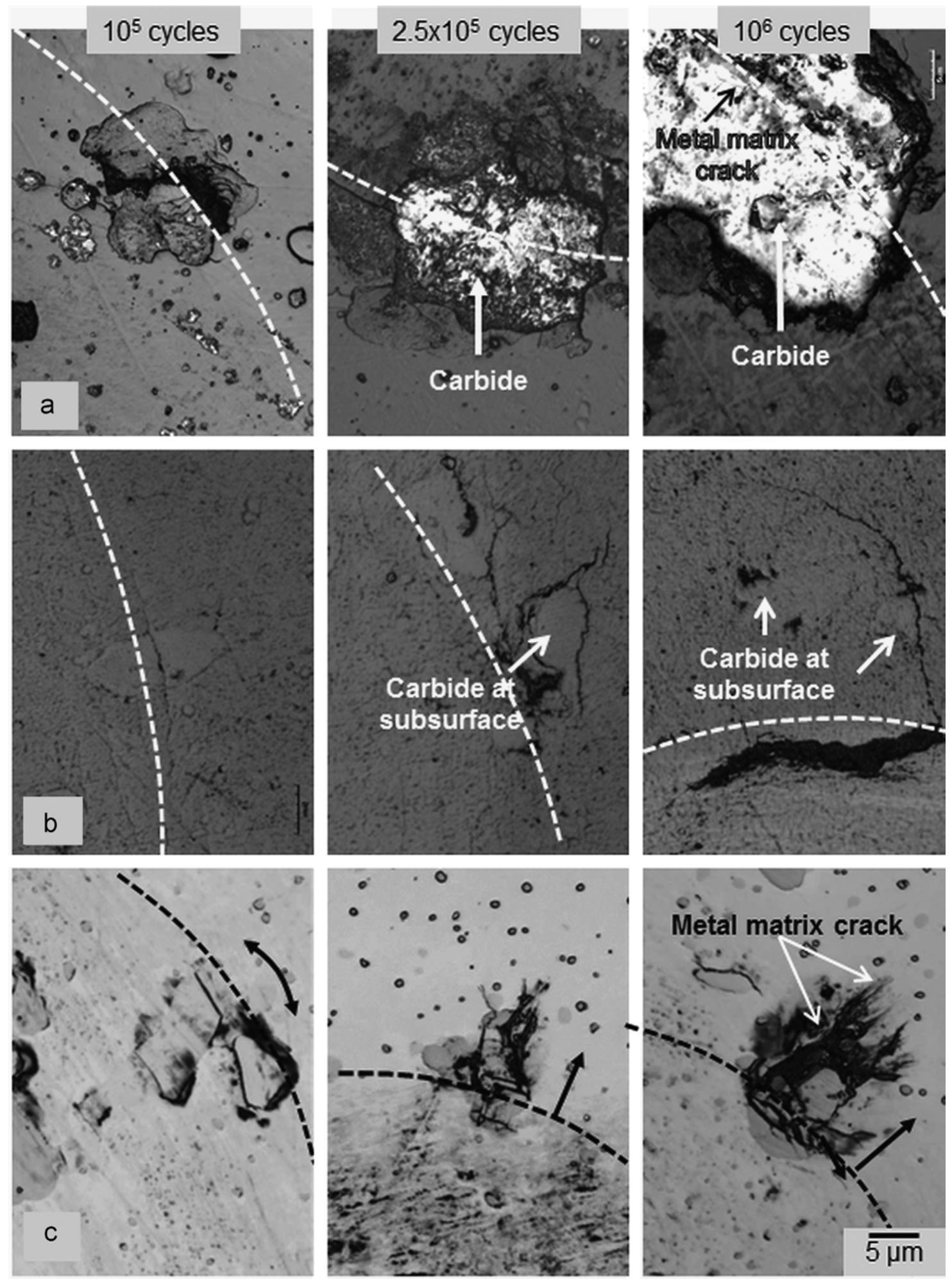

Fig. 7. Indentation under of cyclic loading conditions of: (a) TiN, (b) WC:H and (c) uncoated UNIVERSA steel. The maximum load applied was $800 \mathrm{~N}$. Dot lines represent the edge of residual imprint and blar arrows shows the direction of crack propagation. 
curvature radius, irreversible deformation of the coated systems is evidenced through residual surface traces. Tensile radial stresses and strains existing in the vicinity of the residual imprints rise with number of cycles, until they become large enough for inducing circumferential cracks in both coatings surfaces (already at cycle 1 for WC:H film and after $10^{4}$ cycles for TiN), as shown in Fig. 5. Comparing the responses of both coatings under monotonic loading (and within the low-cycle fatigue regime), earlier cracking of the WC:H coating must be associated with the extremely lower hardness exhibited at its surface. Other factors such as residual stresses (also related to hardness [22]) and fracture toughness, both of them usually lower for amorphous DLC coatings than for crystalline TiN ones [25-28], could also be recalled for rationalizing the different behavior observed. However, these parameters were not explicitly assessed in this study.

Contact fatigue tests were performed to evaluate the susceptibility of the coated tool steels to damage appearance as number of cycles increases, for a maximum applied load of $800 \mathrm{~N}$. Fatigueinduced damage evolution is schematically described for both coated systems in Fig. 6. Micrographs corresponding to insets from residual cyclic indentation imprints for number of cycles ranging from $10^{5}$ to $10^{6}$ are presented in Fig. 7. In this figure, damage scenario for the nude (uncoated) substrate under similar testing conditions is also included for comparison purposes. 
In the TiN-coated system, experimental results (Fig. 6) show that under cyclic loading, coated substrates exhibited accumulated
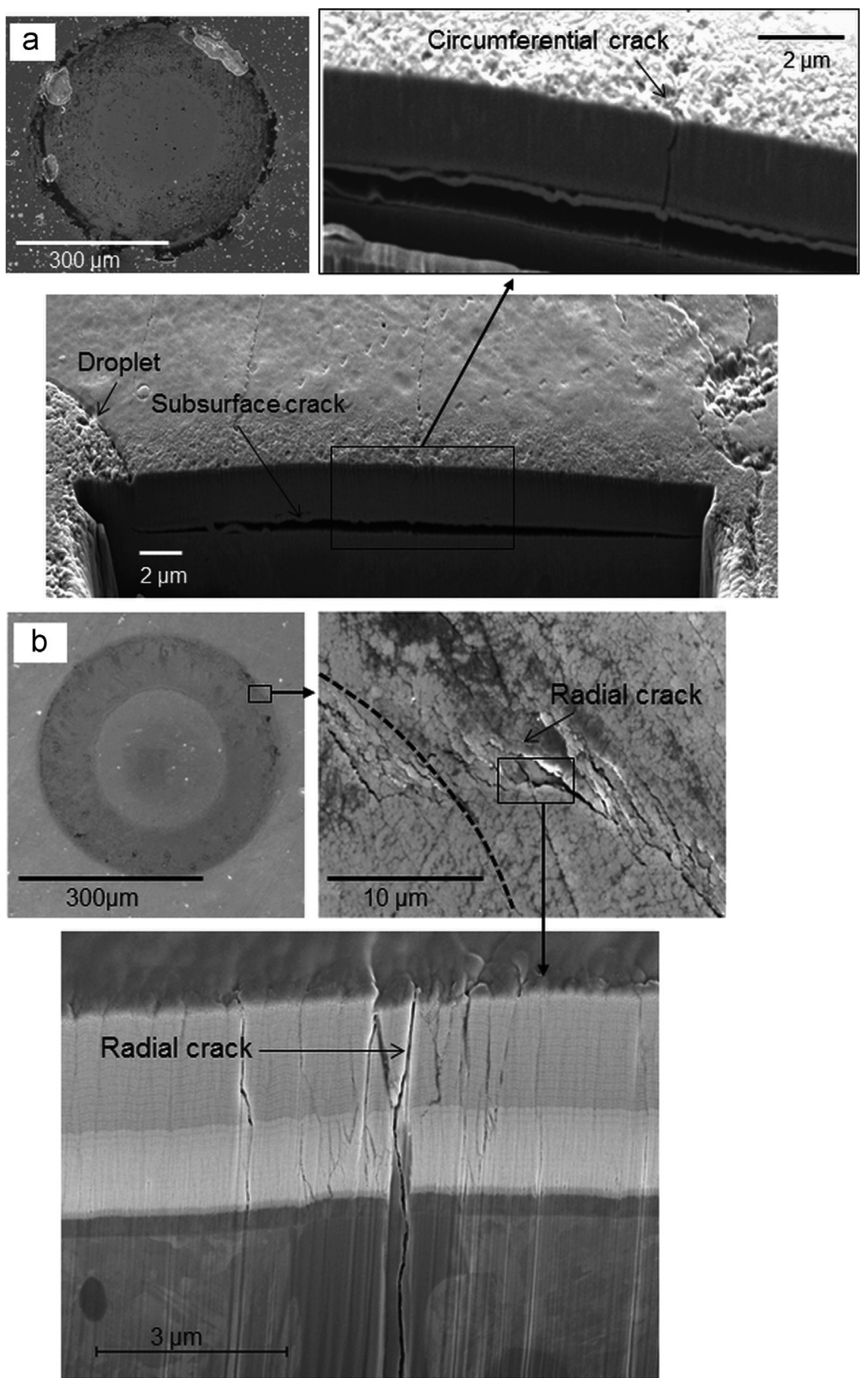

Fig. 8. Cross-section view micrographs of (a) TiN and (b) WC:H coatings deposited on UNIVERSAL steel. Dot lines represent the edge of residual imprint. 
damage as well as evidence of other failure mechanisms which were not observed under monotonic loading (and even after $10^{4}$ cycles). This is clearly seen in Fig. 7a, where it is evidenced that TiN-steel system exhibits, as the number of cycles rises, development of cohesive spallation at the edge of the residual imprint. However, this was not the final failure scenario with extended cycling, as delamination of the ceramic film emerged as an additional damage micromechanism for number of cycles higher than $210^{5}$. On the other hand, besides the referred circumferential cracking already evidenced under monotonic loading, radial cracks are the only additional damage features discerned on the $\mathrm{WC}: \mathrm{H}$ coating surface during fatigue testing up to $10^{6}$ cycles (Figs. 6 and $7 \mathrm{~b}$ ). These radial crack patterns are related with hoop stress variations at the edge of spherical indentation [29,30], and have been also observed in uncoated and coated tool steels at relatively high monotonic applied loads [7].

By comparing the fatigue-induced damage micromechanisms for both coated systems, it is clear that droplets play a critical role as detrimental seeds for cohesive failure of the TiN thin film (Fig. 7a). As the number of cycles increases, droplets tend to induce the detachment of coating. Hogmark et al. [31] described two types of contact stress patterns that must be considered in the design of tribomechanical coatings: (1) the Hertzian contact stresses related to the macroscopic contact geometry, and (2) the stresses associated with the microscopic asperity contacts. In the second case, the highest contact stresses are restricted to the locations of asperity contact, and they usually occur within a few microns from the contact interface. Therefore, droplets at the surface of the TiN coating studied may be considered as localized stress concentrators (microscopical contact zones) that directly affect the mechanical integrity at the surface, interface and substrate subsurface of the overall coated steel under cyclic loading conditions. However, it should be pointed out that spallation of TiN out of the substrate resulted from the interaction between coating cracks/defects and subsurface fissures nucleated within the substrate, as shown Fig. 8a. Tool steel damage evolution within the high-cycle fatigue regime is shown in Fig. 7c, where broken primary carbides and subsequent radial crack propagation into the metal-matrix can be observed.

Concerning the WC:H-coated system, Fig. 7b shows the circumferential/radial cracking scenario found at discrete locations along the indentation imprint periphery. Damage features are neater and clearer discerned than for the TiN-coated system because the smooth and defect-free topography of this DLC layer. Crosssection view (Fig. 8b) permits to assess that multilayer structure of the carbonaceous coating does not have any influence on the crack trajectory pattern throughout the film. By contrast, fissures tend to follow the boundary of columns. It is also evidenced that radial cracking identified at the coating surface is somehow connected with similar damage features within primary carbides (at the subsurface level) of the tool steel. However, it does not develop into any coating detachment, i.e. adhesive failure. Within the context of microscopic asperity contact, the above findings point out the absence of droplets at the surface and the low friction coefficient of the DLC layer (typically around 0.1-0.2, e.g., see Refs. [8,26]) as main reasons for rationalizing the enhanced contact fatigue behavior observed for the $\mathrm{WC}: \mathrm{H}$-coated steel. The former is critical for decreasing amplitude and location of stress concentrations within the coating. On the other hand, the latter would be key for reducing stresses that may induce adhesive failure micromechanisms during contact fatigue, as it ensures that maximum shear stress is located at depths far down from the interface and neighboring substrate subsurface $[8,11,31]$. 
Finally, the observation of rings marks inside the residual imprints (Fig. 9) should be highlighted. They are speculated to emerge as a consequence of a repetitive low amplitude displacement during the cyclic indentation tests due to plastic deformation of the coated systems. The fact that oxidation phenomenon has been detected in the residual imprints for the TiN coating (Fig. 9a) would indicate that flash temperature levels are reached inside the slip region, as a direct consequence of shearing during the referred relative displacement between contacting surfaces. On the other hand, although a ring was also discerned inside the indentation imprint of the WC:H layer, oxidation was not found in this case (Fig. 9b). Accordingly, such absence of any oxidation may be indirectly indicating a transformation of the carbonaceous coating into graphite, as a result of temperature or humidity effects, both variables critical for the surface graphitization of DLC-like layers [12,32].

\section{Conclusions}

In this study the contact fatigue behavior and associated damage micromechanisms of two coated coldwork steel systems have been assessed. Main objective was to compare responses resulting from using coatings with distinct chemical nature (TiN and $\mathrm{WC}: \mathrm{H}$ ) deposited following different PVD routes (cathodic arc and sputtering, respectively). Main conclusions drawn in this investigation may be summarized as

follows:

WC:H-coated system exhibits an enhanced contact fatigue behavior, as compared to the one evaluated for the reference TiN-coated one. Such assessment is done on the basis of the absence in the former of both cohesive and adhesive damage micromechanisms, within the range of testing conditions investigated (i.e., maximum applied load of $800 \mathrm{~N}$ and number of cycles as high as $10^{6}$ ).

The smooth surface topography (free of droplets as direct result from the sputtering deposition process) and the intrinsic low friction coefficient of the WC:H coating are pointed out as the factors responsible for the referred contact fatigue response, as they tend to reduce effective stresses associated with microscopic asperity contacts.

WC:H coating also exhibits a higher oxidation resistance than the TiN layer, this phenomenon being
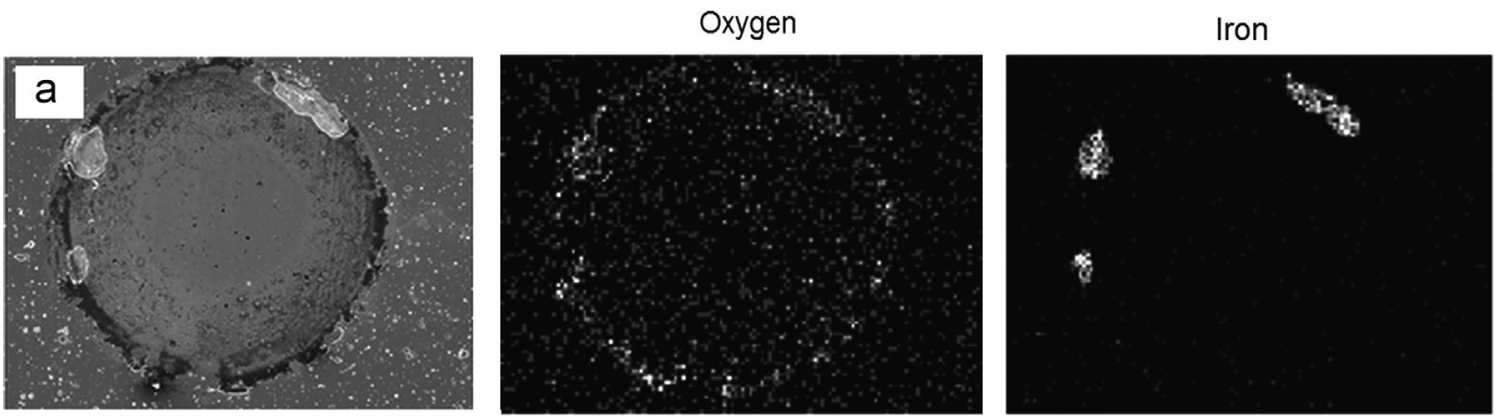

induced

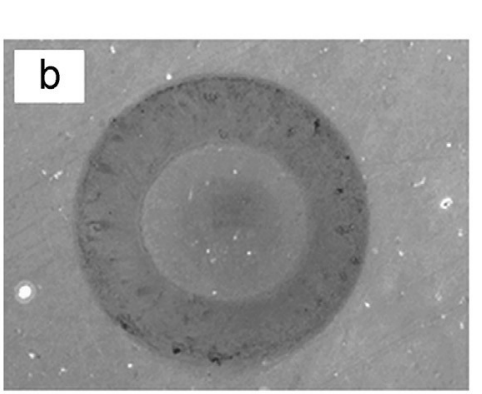

Oxygen Ka1_2

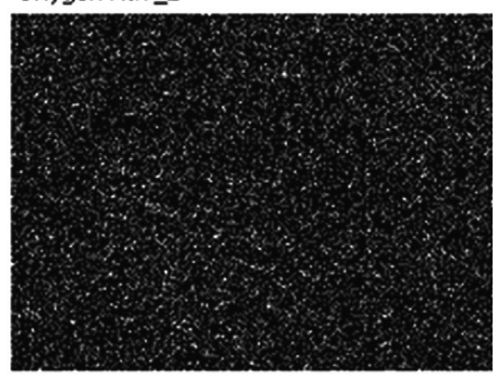

Oxygen Ka1_2
Iron Ka1

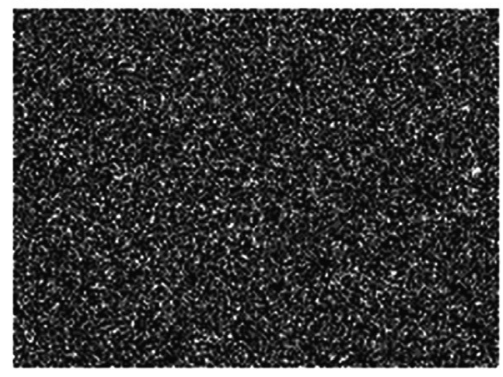

Iron Ka1 by a repetitive smallscale shearing displace ment during the servicelike contact fatigue tests

Fig. 9. SEM image and mapping of oxygen and iron elements of: (a) TiN and (b) WC:H coatings. Residual imprints obtained at $800 \mathrm{~N}$ during $10^{6}$ cycles. 
conducted.

\section{Acknowledgments}

This work was partly founded by Spanish Ministerio de Ciencia e Innovación (oPtiMa-IPT-2011-1376020000) and National Board for Technological and Industrial Development - CDTI (Forma0 - CENIT Program). The authors acknowledge ROVALMA and AIN for supplying the coated systems used. GDOES test assistance by Jonathan Fernandez (AIN) is kindly acknowledged too.

\section{References}

[1] Knotek O, Bosserhoff B, Schrey A, Leyendecker T, Lemmer O, Esser S. A new technique for testing the impact load of thin films: the coating impact test. Surf Coat Technol 1992;54-55:102-7.

[2] Heinke W, Leyland A, Matthews A, Berg G, Friedrich C, Broszeit E. Evaluation of PVD nitride coatings, using impact, scratch and Rockwell-C adhesion tests. Thin Solid Films 1995;270:431-8.

[3] Holmberg K, Matthews A, Ronkainen H. Coatings tribology-contact mechanisms and surface design. Tribol Int 1998;31:107-20.

[4] Bouzakis K-D, Vidakis N, David K. The concept of an advanced impact tester supported by evaluation software for the fatigue strength characterization of hard layered media. Thin Solid Films 1999;355356:322-9.

[5] Batista JCA, Godoy C, Pintaúde G, Sinatora A, Matthews A. An approach to elucidate the different response of PVD coatings in different tribological tests.

Surf Coat Technol 2003;174-175:891-8.

[6] Steyer Ph, Mege A, Pech D, Mendibide C, Fontaine J, Pierson J-F, et al. Influence of the nanostructuration of PVD hard TiN-based films on the durability of coated steel. Surf Coat Technol 2008;202:2268-77.

[7] Ramirez G, Mestra A, Casas B, Valls I, Martinez R, Bueno R, et al. Influence of substrate microstructure on the contact fatigue strength of coated cold-work tool steels. Surf Coat Technol 2012;206:3069-81.

[8] Gahlin M, Larsson M, Hedenqvist P. Me-C:H coatings in motor vehicles. Wear 2001;249:302-9.

[9] Ramírez G, Góez A, Casas B, Valls I, Martínez R, Llanes L. Enhanced contact fatigue behavior of coated tool steels by using PM substrates. In: Tornberg C, editor. PM tool materials programming. Proceedings of the EURO PM2009. Copenhagen, Denmark, EPMA publications; 12-14 Oct 2009. p. 227-32.

[10] Ramírez G, Tarres E, Casas B, Valls I, Martinez R, Llanes L. Contact fatigue behavior of PVD-coated steel. Plasma Process Polym 2009;6:S588-91.

[11] Mao K, Sun Y, Bell T. Contact mechanics of engineering surfaces: state of the art. Surf Eng 1994;10:297-306.

[12] Erdemir A. The role of hydrogen in tribological properties of diamond-like carbon films. Surf Coat Technol 2001;146-147:292-7.

[13] Hauert R. An overview on the tribological behavior of diamond-like carbon in technical and medical applications. Tribol Int 2004;37:991-1003.

[14] Podgornik B, Hogmark S. Surface modification to improve friction and galling properties of forming tools. J Mater Process Technol 2006;174:334-41. 
[15] Michel MD, Muhlen LV, Achete CA, Lepienski CM. Fracture toughness, hardness and elastic modulus of hydrogenated amorphous carbon films deposited by chemical vapor deposition. Thin Solid Films 2006;496:481-8.

[16] Hainsworth SV, Uhure NJ. Diamond like carbon coatings for tribology: production techniques, characterization, methods and applications. Int Mater Rev 2007;52:153-74.

[17] Charitidis CA. Nanomechanical and nanotribological properties of carbonbased thin films: a review. Int J Refract Met Hard Mater 2010;28:51-70.

[18] Kano M. Super low friction of DLC applied to engine cam follower lubricated with ester-containing oil. Tribol Int 2006;39:1682-5.

[19] Picas I, Hernández R, Casellas D, Casas B, Valls I. Mechanical performance of cold forming tools. In: Beiss P, Broeckmann C, Franke S, Keysselitz B, editors. Proceedings of the 8th international tooling conference: tool steels. Aachen, Germany. RWTH Aachen University: 2-4 June 2009 p. 1037-48.

[20] Oliver WC, Pharr GM. Measurement of hardness and elastic modulus by instrumented indentation: advances in understanding and refinements to methodology. J Mater Res 2004;19:3-20.

[21] Anders A. Approaches to rid cathodic arc plasmas of macro- and nanoparticles: a review. Surf Coat Technol 1999;120-121:319-30.

[22] Dekempeneer EHA, Meneve J, Smeets J, Kuypers S, Eersels L, Jacobs R. Structural, mechanical and tribological properties of plasma-assisted chemically vapor-deposited hydrogenated $\mathrm{C}_{\mathrm{x}} \mathrm{N}_{1} \mathrm{x}-\mathrm{H}$ films. Surf Coat Technol 1994;68-69:621-5.

[23] Vercammen K, Haefke H, Gerbig Y, Van Hulsel A, Pflüger E, Meneve J. Surf Coat Technol 2000;133134:466-72.

[24] Strondl C, Carvalho NM, De Hosson J, Th. M, Van der Kolk GJ. Investigation on the formation of tungsten carbide in tungsten-containing diamond like carbon coatings. Surf Coat Technol 2003;162:28893.

[25] Wang JS, Sugimura Y, Evans AG, Tredway WK. The mechanical performance of DLC films on steel substrates. Thin Solid Films 1998;325:163-74.

[26] Wänstrand O, Larsson M, Hedenqvist P. Mechanical and tribological evaluation of PVD WC/C coatings. Surf Coat Technol 1999;111:247-54.

[27] Jayaram V, Bhowmick S, Xie ZH, Math S, M-Hoffman Biswas SK. Contact deformation of TiN coatings on metallic substrates. Mater Sci Eng A 2006;423:8-13.

[28] Holmberg K, Ronkainen H, Laukkanen A, Wallin K, Hogmark S, Jacobson S, et al. Residual stresses in TiN, DLC and $\mathrm{MoS}_{2}$ coated surface with regard to their tribological fracture behaviour. Wear 2009;267:2142-56.

[29] Studman CJ, Field JE. The indentation of hard metals: the role of residual stresses. J Mater Sci $1977 ; 12: 215-8$.

[30] Abudaia FB, Evans JT, Shaw BA. Spherical indentation fatigue cracking. Mater Sci Eng A 2005;391:181-7.

[31] Hogmark S, Jacobson S, Larsson M. Design and evaluation of tribological coatings. Wear 2000;246:2033.

[32] Liu Y, Erdemir A, Meletis EI. An investigation of the relationship between graphitization and frictional behavior of DLC coatings. Surf Coat Technol 1996;86:564-8 [33] . 